\title{
a arte e o afeto na inclusão escolar: potência e o pensamento não representativo
}

\author{
mateus freitas barreiro ${ }^{1}$ \\ universidade estadual paulista - unesp, brasil \\ alonso bezerra carvalho ${ }^{2}$ \\ universidade estadual paulista - unesp, brasil \\ marta regina furlan ${ }^{3}$ \\ universidade estadual de londrina - uel, brasil
}

resumo

Este artigo tem o objetivo principal de investigar a arte e o afeto como possibilidade de potência no processo inclusão escolar, tendo como referencial teórico, principalmente, os pensamentos de Deleuze e Guattari. A discussão se inicia pela formação conceitual da noção afeto (affectus) e seus outros componentes conceituais que envolvem a potência e o pensamento não representativo. Atualmente a inclusão escolar faz parte do registro de uma lógica representativa que codifica a experiência do sujeito e reduz sua potência afetiva. Nesse prisma, a arte como experiência estética constitui uma forma de ampliar a potência, uma vez que os afetos são potencializados para um olhar diferenciado na forma de perceber e viver a vida. A metodologia é de cunho teórico, com reflexões acerca dos afetos na relação com o devir deficiente na escola, na sua articulação com a arte e a experiência estética e, envolve o reconhecimento das desigualdades sociais, psicológicas entre outras. Nesse sentido, a arte amplia o afeto não apenas nos sujeitos considerados possuidores de cultura, mas a apreciação depende de uma percepção sensível e, menos de um pensamento representativo.

palavras-chave: arte; afeto; inclusão escolar;

\section{art and affection in school inclusion: potency and non-representative thinking}

abstract

This article has as main objective to investigate art and the affection as options of will to power in the school inclusive process, having as theoretical reference, mainly, the thoughts of Deleuze and Guattari. The discussion begins in the conceptual formation of the notion affect (affection) and its other conceptual components that involve the will to power and the no representative thought. It is now necessary to include a new version of the register of a representative logic that encodes the subject's experience and reduces his/her affective power. In this perspective, the art as aesthetic experience is a way of amplifying power, once they are affected, they are empowered to a differentiated perspective in the means of conceiving and living life. The methodology is theoretical, with reflections on the affections in their relation with the deficient still to come? in the school, in its articulation with art and the aesthetic experience, and it involves the recognition of the social, psychological inequalities, among others. In this sense, art extends the affections, not only in the subjects under consideration, which possess a cultural background, but the appreciation depends on a sensible perception more than on a representative thinking.

\footnotetext{
${ }^{1}$ E-mail: mateusfbb@gmail.com

2 E-mail: professoralonso@yahoo.com.br

${ }^{3}$ E-mail: marta.furlan@yahoo.com.br
} 
keywords: art; affection; school inclusion; deleuze.

\section{el arte y el afecto en la inclusión escolar: potencia y pensamiento no representativo}

resumen

Este artículo tiene el objetivo principal de investigar el arte y el afecto como posibilidad de potencia en el proceso de inclusión escolar, teniendo como referencial teórico, principalmente, los pensamientos de Deleuze y Guattari. La discusión se inicia por la formación conceptual de la noción afecto (affecus) y sus otros componentes conceptuales que involucran la potencia y el pensamiento no representativo. Actualmente la inclusión escolar forma parte del registro de una lógica representativa que codifica la experiencia del sujeto y reduce su potencia afectiva. En este prisma, el arte como experiencia estética constituye una forma de ampliar la potencia, una vez que los afectos son potencializados para una mirada diferenciada en la forma de percibir y vivir la vida. La metodología es de cuño teórico, con reflexiones acerca de los afectos en la relación con el devenir deficiente en la escuela, en su articulación con el arte y la experiencia estética y, implica el reconocimiento de las desigualdades sociales, psicológicas entre otras. En este sentido, el arte amplía el afecto no sólo en los sujetos considerados poseedores de cultura, sino que la apreciación depende de una percepción sensible $\mathrm{y}$, menos de un pensamiento representativo.

palabras clave: arte; afecto; inclusión escolar; deleuze. 
a arte e o afeto na inclusão escolar: potência e o pensamento não representativo

\section{introdução}

A concepção de afeto é bastante extensa e encontra-se diluída na filosofia, educação, história da arte e em outras áreas do conhecimento. Este tema transita pelos diversos campos do saber desde a Grécia Antiga até os dias atuais, mas sem se esgotar, pois os afetos estão presentes em qualquer relação humana de um determinado tempo e cultura.

Na filosofia de Deleuze, o afeto faz parte de uma ordem sensível, que se opõe à ideia de interpretação dos afetos em códigos sob os quais a realidade é remetida a uma narrativa lógica. Por outro lado, a inclusão escolar faz parte do registro de uma lógica representativa que codifica a experiência do sujeito e reduz sua potência afetiva. Nesse prisma, a arte como experiência estética constitui uma forma de ampliar a potência afetiva, possibilitando que os afetos se mobilizem para um olhar diferenciado na forma de perceber e viver a vida, ou seja, para a inclusão escolar. É preciso salientar, que a inclusão escolar não se trata de um processo de inserir alunos em uma escola que trabalhe com discursos marcados pela moralização de um suposto humanismo ou de uma visão logocêntrica sobre a educação. O uso comum do termo "inclusão escolar", faz parte de uma representação que remete a um modelo de aluno normal. Os nomeados "alunos deficientes" são os que não se enquadram nesse modelo instituído pela escola.

Assim, visando acrescentar uma perspectiva diferenciada sobre a inclusão escolar, o presente texto visa refletir sobre a arte como experiência estética e a sua articulação com a inclusão escolar. Tem como objetivo tratar sobre a arte e o afeto para repensar novas possibilidades de inclusão escolar, tendo como referencial teórico, principalmente, o pensamento de Deleuze (1978, 1987 1995, 1997, 2002) e, Deleuze e Guattari (1992). Didaticamente o texto analisa o conceito de afeto e seus componentes, visando responder como a arte e a experiência estética pode contribuir com a inclusão escolar, visando ressignificar o ensino e a aprendizagem, a partir da diferença, sem que haja um modelo em particular para a ser reproduzido. 
Para tanto, será discutido o conceito de afeto e seus componentes nas obras de Deleuze, especialmente em O que é Filosofia? (1992) e Mil Platôs (1995), ambos escritos com Felix Guattari, e em Espinosa: Filosofia Prática (2002) e Proust e os signos (1987).

A primeira consideração a ser realizada, é que a discussão sobre o conceito de afeto não visa apenas reproduzir um conhecimento filosófico, pois fazer filosofia para Deleuze, é situar-se no pensamento para responder a um novo problema. Comecemos então, a investigar a noção "afecto" (affectus) e seus outros componentes conceituais que serão trabalhados para levantar o problema do pensamento não representativo. Em Ética, principal obra de Espinoza escrita em latim, encontram-se dois termos distintos e com diferentes significados, o "affectus" (afeto) e "affectio" (afecções):

Afecção remete a um estado do corpo afetado e implica a presença do corpo afetante, ao passo que o afeto remete à transição de um estado a outro, tendo em conta variação correlativa dos corpos afetantes (DELEUZE, 2002, p. 56).

Logo de início, é preciso destacar que o afeto e a afecção estão sempre interligados. A afecção representa um estado momentâneo do corpo, ao passo que o afeto é a passagem de um estado a outro, é uma transição (transitio). A proposta de estudar o afeto e as afecções justifica-se plenamente pela pertinência do mesmo enquanto tema de estudo. Do ponto de vista político, a questão do afeto envolve as relações entre os governantes e os cidadãos. Deleuze (1978) lembrava em suas aulas a forma que Espinosa introduzia a questão política ao discutir o afeto. Quando os déspotas e os sacerdotes afetavam seus súditos de maneira negativa, eles eram tomados por afetos tristes. E a tristeza é o afeto que envolve a diminuição da potência de agir, levando-nos para uma perfeição menor. Assim, os súditos tristes reforçam o poder dos déspotas.

Para posicionarmos a questão do afeto no âmbito da discussão entre filosofia e educação, comentaremos as principais obras de Deleuze e Guattari que auxiliaram a compreender como foi construído o conceito de afeto e de afecção. 


\section{a arte $e$ os afetos}

Segundo Deleuze e Guattari (1992, p. 29), todo conceito tem uma história, embora se desdobre em ziguezague e cruze talvez outros problemas ou planos diferentes. Sob esse ponto de vista, o conceito apresenta-se, na maioria das vezes, "com pedaços ou componentes vindos de outros conceitos, que respondiam a outros problemas e supunham outros planos" (DELEUZE; GUATTARI, 1992, p. 29). Por outro lado, do ponto de vista de seu devir um conceito mantém relação com outros conceitos, mas desta vez situados no mesmo plano. Aqui, afirmam Deleuze e Guattari:

Os conceitos se acomodam uns aos outros, superpõem-se uns aos outros, coordenam seus contornos, compõem seus respectivos problemas, pertencem à mesma filosofia, mesmo se tem histórias diferentes. Com efeito, todo o conceito, tendo um número finito de componentes bifurcará sobre outros conceitos, compostos de outra maneira, mas que constituem outras regiões do mesmo plano, que respondem a problemas conectáveis, participam de uma co-criação (DELEUZE; GUATTARI, 1992, p. 30).

Primeiramente, tanto o pensamento de Deleuze e Guattari (1992) quanto o de Spinoza, estavam em torno da criação do conceito afeto e afecção. Deleuze fez mais do que repensar, fez de alguma forma o pensar em Spinoza, alojando-se no interior do elemento teórico, do meio vivo onde se constrói toda sua obra, sem que fosse reduzida a uma combinação doutrinal, a um sistema, tão pouco se restringir a entrar em contato com uma filosofia, como a de Spinoza, como ela é e, descrever seu discurso de forma objetiva e exaustiva, de uma perspectiva estática, mas sim, dinamicamente, produzida como se fosse a primeira vez, o movimento intelectual que a fez tornar o que é. A filosofia de Spinoza é permeada pelo olhar atento e cuidadoso que direciona ao campo da experiência enquanto manifestação do jogo das relações humanas.

Na obra O que é filosofia? (1992), foi discutido sobre as diferenças entre as formas da produção de pensamento e conceitos, seja na filosofia, ciência ou arte. Este processo de produção de pensamentos e conceitos, se desdobram em diferentes campos do conhecimento: a filosofia cria conceitos, a ciência cria funções e a arte sensações. Dentre esses três ramos do conhecimento, 
destacaremos o enfoque dado por Deleuze à arte, pois é ela em sua heterogeneidade a responsável por compor afetos que proporcionam as experiências estéticas e, responsável pelo desencadeamento do devir sensível; uma vez que, em arte não se trata de reproduzir ou criar formas, mas de captar forças.

No decorrer de toda sua trajetória intelectual, Deleuze sempre atribuiu à arte um tema de destaque em suas entrevistas, aulas e obras que foram dedicadas a pensar a experiência estética como um modo viver a diferença em suas múltiplas faces. Quando Deleuze trata do conceito de arte ao longo de suas obras, não há uma tentativa em limitar-se a avaliar as relações entre a vida e a obra de qualquer artista, mas no sentido da arte enquanto criadora de sensações e experiências.

Ainda, a arte em Deleuze poderá ser repensada a partir de outros problemas, como é o caso da inclusão escolar, pois o aprendizado do artista tem em comum com a inclusão escolar, o fato de não estar precedido apenas pela inteligência, mas pelo encontro com o inesperado, com o acaso, com a produção de afetos. Ao colocar o problema da inclusão escolar do ponto de vista da arte, é colocá-lo como um modo de criação fora de uma óptica logocêntrica. Nesse sentido, remetemo-nos as palavras de Deleuze e Guattari (1995, p. 17) quando diz: "não somos mais nós mesmos. Cada um reconhecerá os seus. Fomos ajudados, aspirados, multiplicados".

Em todas as artes, o artista é quem apresenta, inventa e cria os afetos em relação às perspectivas que eles nos dão. Somos afetados e nos transformamos através da produção de suas obras (DELEUZE; GUATTARI, 1992, p. 227). A obra de arte forma um "bloco de sensações, isto é, um composto de perceptos e afectos" (DELEUZE; GUATTARI, 1992, p. 213). Os perceptos não são percepções, os afetos não são sentimentos ou afecções, mas sim devires não humanos. "A sensação não se realiza no material, sem que o material entre inteiramente na sensação, no percepto ou no afecto. Toda matéria se torna expressiva" (DELEUZE; GUATTARI, 1992, p. 217). Assim, para os autores, independentemente, do gênero artístico todos expressam por meio de sensações. No entanto, as sensações, assim como os 
perceptos, não são percepções que remetem a um objeto ou referente, nem mesmo se identificam ao material, mantendo com esta outra modalidade de relação.

Os perceptos não mais são percepções, são independentes do estado daqueles que os experimentam; os afectos não são mais sentimentos ou afecções, transbordam a força daqueles que são atravessados por eles. As sensações, perceptos e afectos, são seres que valem por si mesmos e excedem qualquer vivido (DELEUZE; GUATTARI, 1992, p. 213).

Em relação a experiência estética que o afeto proporciona, esta função enaltece o papel do visível para invisível, ao passar do perceptível para o imperceptível ou, nos termos utilizados por Deleuze e Guattari, a "máquina de guerra" (O’SULLIVAN, 2001, p. 130). A potência da obra de um artista não é representativa, pois o espectador apreende, produz e reverbera a partir da obra de arte carregada de afetos. Segundo Farina (2005, p. 82), a obra de arte e a sua singularidade conceitual, coloca em circulação, o fazer circular de uma nova maneira, a realidade que está fortemente contida nos acontecimentos do campo subjetivo. Nesse sentido, Deleuze não visou entender apenas a arte ou o sujeito, mas ver como através das linhas de fuga, o sujeito se modifica e ultrapassa o regimento das instituições demarcadas pela sua normatização.

A tentativa de compreender as afecções na inclusão escolar, poderá abrir horizontes para que a passagem do afeto de tristeza se transmute para outro de alegria, dadas as circunstâncias em que essa passagem de um afeto a outro seja transmutada, por exemplo, na relação professor-aluno ou aluno-aluno. Nesse sentido, ao estabelecermos esse olhar sensível para o outro, passamos a interagir com o outro e pelo outro, na busca da capacidade de afetar e ser afetado em um tempo, assim como afirma Deleuze (2002).

Contudo, é inevitável que existam algumas tristezas, mas é fundamental que as tristezas possam ser trabalhadas para que não se torne algo destrutivo no processo de inclusão escolar, pois os alunos, tendem a se enamorar com a escola a partir da alegria provocada pelas relações entre os corpos. Para o aluno sentir-se incluído na escola, é preciso de um encontro com alguma coisa que os afete positivamente, volta-se para o ativar das paixões alegres, evitando à passividade e a submissão dos poderes instituídos. 
A criação pode ocorrer por vias da afecção, que é o efeito de um corpo sobre o outro, porém, podendo ficar separado daquilo que é capaz, ou seja, a potência. Quando esta separação ocorre, a capacidade de agir é suprimida, passa-se a viver inúmeras prescrições a serem simplesmente reproduzidas, quanto atender as demandas que lhe são solicitadas. Assim, resta-nos perceber a arte, também como uma afetação que rompe com os dispositivos de poder, das estratégias de saber e dos processos de subjetivação que ocorrem no campo escolar.

Portanto, um dos modos de pensar a inclusão escolar, é a arte, pois ela cria ressonâncias nos modos de vida, e produz afetos que permeiam a singularidade de cada sujeito aluno. Em Deleuze e Guattari (1992) a sensação remete a um devir, pois implica um “tornar-se" e, está longe de ser algo comparado ao processo de imitação ou identificação; tão pouco, de ser a adequação e a formatação de um modelo ou representação. Para os autores, os devires são fenômenos de dupla captura, pois, quando alguém ou algo se transforma, aquilo em que ele se transforma muda tanto quanto ele próprio.

É de toda a arte que seria preciso dizer: o artista é mostrador de afectos, inventor de afectos, criador de afectos, em relação com os perceptos ou as visões que nos dá. Não é somente em sua obra que ele os cria, ele os dá para nós e nos faz transformar-nos com ele, ele nos apanha no composto (DELEUZE; GUATTARI, 1992, p. 227228).

Em Espinosa: Filosofia Prática, Deleuze (2002) repensou a questão do afeto ao abordar o conceito de ideia. A explanação desta combinação e diferenciação de natureza entre ideia e afeto nos dá a fundamentação necessária para investigar a formação de um pensamento não representativo. Segundo Gleizer (2005, p. 3), o termo afeto (affectus) expressa a transição (transitio) de um estado a outro no corpo afetado e no corpo afetante. Essa transição pode ser boa ou ruim para o corpo afetado, que é definido pelo aumento, no primeiro caso, ou diminuição, no segundo, da potência de agir do corpo. Os afetos são ideias, ao passo que as afecções (affectio) são modificações que acontecem no corpo e na mente, mas não são representações de objeto, visto que exprimem as transições de potência entre um estado e outro. 
A ideia é representativa, mas devemos diferenciar a ideia que somos (o espírito como ideia do corpo) das ideias que temos. Assim temos a realidade objetiva e formal: "a realidade objetiva de uma ideia é o objeto que ela representa, e a sua realidade formal é tal que somos por ela afetados, de acordo com sua perfeição" (REBELLO, 2005, p. 49). A representação inerente à noção de ideia, remete a uma perspectiva que ocupa lugares comuns na História da Filosofia, um pensamento majoritário, que coloca a noção de representação ou imaginário como uma verdade evidente. Não obstante, a relação entre ideia e afeto não se restringe apenas a uma oposição entre pensamento representativo e o não representativo, pois as ideias tidas como realidades formais designam objetos que sucederão em uma afetividade sobre tais objetos.

Um discurso lógico ou representativo, tende a ser um saber hegemônico que compreende o afeto sob um olhar que é exterior ao sujeito. Desse modo, um viés dicotômico estaria posto quanto à questão da representação encerrada em si mesma, pois a representação é um modo de compreender a realidade a partir da relação entre exterior-interior e objetivo-subjetivo. Em contraposição a uma lógica representativa, o pensamento poderá ser expresso em um plano sensível, que é possível desejar além das coordenadas estabelecidas no processo de inclusão escolar, tornando como possibilidade a suspensão de dinâmicas normalizadoras que marginalizam os afetos do ser humano.

Outra crítica pertinente que Deleuze faz em relação ao pensamento representativo e sua relação com a aprendizagem, se encontra na obra Proust e os signos (1987), em que o signo 4 é concebido como algo que exerce uma ação direta sobre a subjetividade, sem a mediação da representação. Os signos são emitidos por matérias, objetos, pessoas, mas não são formas, objetos ou sujeitos. Deleuze se questiona, como a arte e a literatura podem contribuir a respeito da aprendizagem. Segundo Deleuze (1987), não se sabe ao certo como uma pessoa aprende; mas, de qualquer forma que aprenda, é sempre através dos signos, perdendo tempo, e não pela assimilação de conteúdos objetivos (DELEUZE, 1987, p. 21). Esse problema é

\footnotetext{
${ }^{4}$ Deleuze conceitua os signos em quatro sistemas: signos mundanos, signos amorosos, signos sensíveis e signos artísticos (DELEUZE, 1987).
} 
interessante, visto que a inclusão escolar tende a ser discutida apenas por uma lógica normativa, e não como algo inventivo ${ }^{5}$, que envolve afetos, percepções, sensações e imaginações.

O livro de Deleuze sobre Proust constitui um extenso trabalho sobre o conceito de signo, que se trata de um modo para se pensar a invenção de problemáticas associadas à construção do conhecimento e a experiência estética, que incluem os signos artísticos ${ }^{6}$. O objeto da atividade criativa do aprender são os signos e o objetivo de um aprendizado é explicitar os sentidos dos signos, mas para um mesmo signo é possível produzir modalidades de pensamentos a partir de outra perspectiva. Aprender é levar em consideração uma matéria ou um objeto como se estes apresentassem signos a serem assimilados por sensações, sem que haja uma vinculação restrita com a inteligência e a busca de uma verdade.

Além da relação entre os sentidos dos signos para a mobilização das sensações e dos afetos, a leitura que Deleuze faz de Espinosa, ainda trabalha a importância do corpo em relação à transição da afecção para o afeto. A afecção apresenta uma relação imanente com o corpo, pois a afecção é o efeito de quaisquer corpos em relação ao nosso corpo, na medida em que, um corpo tido como realidade objetiva para uma ideia e compondo sua realidade formal afetanos de algum modo. É nesse sentido, que a escola poderia envolver os alunos em situações que possibilitem a interação entre os pares, possibilitar um encontro um bom-encontro de corpos, a fim de que a escola e o educador desenvolvam o agir mediador entre alunos, em favor da constituição de relações humanas que façam a transição de afetos entre os sujeitos envolvidos. Ainda, essas variações atuam na

\footnotetext{
5 Segundo Bergson (1948), a invenção apresenta dois domínios. Primeiramente, a invenção é sempre invenção de novidade, sendo, por definição, imprevisível. Em segundo lugar, para Bergson a invenção, é sempre invenção de problemas e não apenas invenção de solução de problemas. Nas escolas, o processo de inclusão escolar, tende negligenciar o caráter imprevisível do processo de aprender e a invenção de problemas. O caráter imprevisível se remete a um signo sensível que se devem aos encontros que ressoam sensações e memórias involuntárias.

6 Os signos artísticos fazem parte da descoberta do tempo como "tempo puro", "tempo original absoluto" e "tempo primordial" (MACHADO, 2009). Estes signos que envolvem a experiência estética, poderão abranger o cinema, a música, a pintura e a literatura em um tempo redescoberto e original absoluto.
} 
potência de agir, ou seja, como o afeto enquanto acontecimento poderá variar a potência de existir, aumentando (alegria) ou diminuindo (tristeza).

Os afetos (alegria/tristeza) dizem respeito a estarmos sujeitos aos aumentos e diminuições de nossa potência de agir. No entanto, é recorrente estarmos temporariamente menos fixados a essa variação quando nossa potência de agir é aumentada, ou seja, quando somos afetados pela alegria, desejamos permanecer assim. Então, a amplitude da potência de agir gera um impulso para nos manter afetados de alegria, mas quando somos afetados pela tristeza, a potência de ação está em um nível baixo. Para entendermos como possivelmente ocorre esta variação7, explicitemos um exemplo que Deleuze utilizou em sua aula sobre Espinosa:

Eu cruzo na rua com Pedro, com quem antipatizo, e depois passo por ele, e digo "Bom-dia, Pedro", ou então sinto medo e depois, subitamente, vejo Paulo, que é tremendamente encantador, e eu digo "Bom-dia, Paulo", tranquilizado e contente. Bem. O que acontece? Por um lado, sucessão de duas ideias, ideia de Pedro e ideia de Paulo; mas há outra coisa: também operou em mim uma variação (DELEUZE, 1978, p. 3).

A sucessão da ideia de Paulo à de Pedro, favorece a força de existir, sendo que a potência de agir é aumentada ou diminuída; inversamente, se depois de ver alguém que me deixava alegre vejo alguém que me deixa triste, portanto, a potência de agir é inibida ou impedida (DELEUZE, 1978, p. 4). Nesse sentido, poderemos começar a pensar em encontros que vão além do espaço institucional, que tornam os vínculos afetivos um acontecimento que ultrapassa as normas de uma instituição, como no caso dos encontros que ocorrem dentro e fora da escola, em que diferentes atores tornam esses encontros algo favorável ou desfavorável em relação à potência de agir.

Em Mil Platôs, a questão do afeto volta a ser tratada, mas inserida em um plano etológico (DELEUZE; GUATTARI, 1997, p. 42). Neste plano, em que afeto poderá aumentar ou diminuir a potência, é exemplificado através do carrapato, que se define por seus afetos. O carrapato atraído pela luz vai até o ponto mais

\footnotetext{
${ }^{7}$ Espinosa não utilizou o conceito de variação, mas Deleuze utilizou o termo (variação) da força de existir ou outra palavra que ele emprega como sinônimo: "vis existendi", a força de existir, ou "potentia agendi", a potência de agir (DELEUZE, 1978, p.3).
} 
alto da árvore, ficando à espreita de algum mamífero que passe ao seu redor, para se alojar debaixo da pele do animal, chupando seu sangue. Três elementos externos afetam o carrapato: a luz, o odor e o sangue. Sua potência pode ser compreendida por se situar entre dois limites, ele pode ficar por muito tempo em jejum na floresta ou depois poderá se alimentar com sangue, acarretando em sua morte (DELEUZE; GUATTARI, 1997, p. 42-43).

Esta discussão do afeto em um plano etológico, sem dúvidas, pode ser ampliada ao campo clínico, como Deleuze e Guattari o fez ao discutir o caso do pequeno Hans, de Freud: “o cavalo do pequeno Hans não é representativo, mas afetivo" (DELEUZE; GUATTARI, 1997, p. 42-43). A partir deste caso clínico do pequeno Hans, Deleuze e Guattari (1997, p. 43) identificam os afetos que permeiam e se transformam a partir do agenciamento: o que pode um cavalo. $\mathrm{O}$ cavalo não é caracterizado como membro de uma espécie, mas faz parte de um agenciamento maquínico como um elemento ou indivíduo que compõe a relação. Ao pensar nas diferentes leituras sobre o caso do pequeno Hans, como poderemos experimentar os afetos que rompam com uma visão representativa e normatizadora na inclusão escolar?

O método como o cavalo foi concebido por Freud através de uma representação simbólica, diz respeito à psicanálise ser constituída como um modelo clínico que dependente da relação entre a linguagem e interpretação hermenêutica. No entanto, aquele que é denominado deficiente, e precisa ser incluído, poderá ressignificar seus afetos por outras formas expressão, pois a interpretação poderá suprimir o que realmente o "deficiente" tem para dizer e sentir. Por exemplo, no caso de uma criança com Autismo, a criança em suas brincadeiras, suas expressões afetivas, tende a ser entendida como um objeto de interpretação sob a óptica do analista, ou ainda, a criança poderá se tornar visível apenas no processo de inclusão escolar, mas poderá ocorrer, dos educadores apresentarem uma visão de inclusão que seja restrita aos parâmetros de normalidade e anormalidade. A normalidade é um padrão utilizado para delimitar um modo específico de existência, e a partir do qual se pode estabelecer 
a anormalidade. A partir da lógica binária entre normal-anormal, os alunos que precisam ser incluídos, são os que se distanciam desse modelo instituído e legitimado pela escola.

\section{o devir deficiente na escola: a arte e o afeto}

O devir deficiente não diz respeito a uma condição existencial ou metafísica, mas significa entender que a deficiência está implicada em um jogo político que tende a normalizar e classificar. Neste caso, o devir deficiente pode ser assumido no modo de uma ontologia política, que possa evidenciar como ocorre nossa concepção existencial e um meio de ser atravessado por essa virtualidade (CARVALHO, 2014, p. 3)

Ao pensar as sanções normatizadoras que envolve um devir deficiente, poderemos recorrer à arte como um modo de produção de afetos para tentar romper com as normas que diminuam a potência agir, culminado em um processo de desterritorialização das instituições que carregam representações preconcebidas sobre como a deficiência deve ser restrita a uma sanção externa. Acrescentemos ainda, ao retomar a discussão sobre a inclusão escolar, se encontra no âmbito dos pensamentos hegemônicos, que visam transformar aquilo que é diferente em um padrão de normalidade.

A educação inclusiva não quer olhar para esse outro, para a deficiência e a diferença, com o intuito de aceitar como ela é, em uma diferença que se repete, que é diferente em cada pessoa. A chamada educação inclusiva não se mostra disposta a acolher a diferença da deficiência ou uma disfunção produzida em outrem, por um acidente genético que através de uma imprevisibilidade, obrigaria a pessoa a se deslocar, a se modificar e a compor um outro olhar não apenas sobre esse outro, como também sobre si mesmo (PAGNI, 2015, p. 111).

Além disso, é comum que haja a exclusão do deficiente no que diz respeito à possibilidade afetiva de ter diversos modos de amizade, namoro ou casamento. Esses estereótipos são sustentados por representações de valores sociais irrefletidos, que as instituições como a escola, tendem a reproduzir valores morais que são moldados por padrões de tal normalidade de vida, de sentimento, de 
ideias e de comportamento humano, desconsiderando no espaço formativo educacional as potências afetivas e a singularidade de cada sujeito aluno.

Pode se destacar, que nas últimas décadas, a inclusão escolar e as lutas dos movimentos em prol das minorias no Brasil, alcançou importantes conquistas na garantia dos direitos civis que ampliaram os direitos dos deficientes. Além das legislações sobre a inclusão do deficiente, o segundo movimento consiste em conviver no cotidiano da deficiência enquanto corporificação, ou seja, a deficiência não pode ser entendida apenas em forma de lei ou conhecimento científico, mas é preciso desenvolver a sensibilidade de afetar e ser afetado por aqueles que sofrem exclusões sociais; potencializando a sensibilidade de afetar e de agir entre os pares.

Para Pagni (2015b, p. 92), na atual conjuntura global, as práticas ditas inclusivas ocorrem na esfera das políticas públicas, com o propósito de garantir os direitos das minorias, sob o influxo de movimentos sociais, porém, é comum que haja uma lógica que se identifica com a economia do capital humano, em que é visado valorizar as diferenças que podem favorecer as inovações, a eficiência no empreendimento de si e enfim, a mobilidade mercado. Desse modo, a inclusão escolar vista sob uma lógica mercantil, tende a legitimar o próprio funcionamento das instituições que visam adaptar a deficiência ao que é concebido como normalidade, na qual os educadores tendem a privilegiar o desenvolvimento apenas da esfera cognitiva, e ainda podendo excluir a possibilidade do deficiente criar afetos e afetar aqueles que se consideram "normais".

Essa questão merece uma reflexão mais aprofundada, pois quando se pensa na educação inclusiva, é praticamente a tentativa de que o deficiente seja afetado pela relação com os sujeitos da normalidade, devendo se adequar ao dito normal. Entretanto, os alunos na sua normalidade precisam ser afetados pelo devir deficiente, assim podemos pensar em inclusão escolar. Para isso, os espaços educacionais precisam se desvincular dos modelos escolares pré-fabricados, permitindo o novo, o diferente.

Segundo Miguel (2015, p. 58), na filosofia de Deleuze, foi enfatizado, em seus textos sobre Deligny, o método cartográfico, que não tem o propósito de 
interpretar o comportamento das crianças, mas de identifica/localizar espacialmente (repérer) os movimentos dela. A crítica feita por Deligny em relação à interpretação da linguagem é justamente o fato do simbólico ser o único modo de alcançar uma verdade.

No caso das psicoses e do autismo profundo, o acesso ao simbólico é interrompido, fraturado ou inexistente, esse aparelho-linguagem não funciona e é por outra via que terá que se trabalhar (MIGUEL, 2015, p. 58). A interpretação supõe um simbolismo para dar sentido a algo, como no caso da psicanálise, em que a relação entre terapeuta e paciente, culmina em uma teoria do conhecimento. No caso dos jogos de verdade, que fazem parte da inclusão escolar, tendem a estarem inscritos a partir de pressupostos universais que não abarcam a natureza múltipla do próprio sujeito que é denominado deficiente. Por isso a importância da arte para produzir afetos, pois a inclusão escolar se desprende do âmbito exclusivo da linguagem e permite ao sujeito ocupar um devir que é seu, mas sem que algo externo o molde sobre outro valor social ou epistemológico.

Basta lembrar da obra de Sloterdijk, intitulada "You must change your life", na qual foi reconstituída a história do menino Unthan (1848-1929), que nasceu sem os dois braços, mas aos seis ou sete anos, descobriu casualmente a possibilidade de tocar violino. Ele desenvolveu a habilidade de tocar o violino com os pés, sendo reconhecido por músicos como Johann Straus e Franz Liszt. Mas Sloterdijk (2012, p. 63) faz uma ressalva de que o heroísmo de Unthan, é um tipo de heroísmo para adentrar em uma normalidade e se converter em um prêmio para a sua anormalidade. Portanto, fica evidente no desenvolvimento da vida de Unthan, que a excentricidade patológica se converteu no pressuposto de uma adaptação exitosa (SLOTERDIJK, 2012, p. 63). O caso de Unthan oferece diversos elementos para se refletir sobre a inclusão do devir deficiente nas escolas, mediante ações equitativas de acesso à educação, que envolvem o fazer artístico na produção de afetos.

Por fim, é preciso que o deficiente não seja desvalorizado pelas suas diferenças, mas os educadores devem estar preparados para trabalhar os afetos, a partir de uma linha de fuga que fornece outro ponto de vista, em que o recorte da 
existência do deficiente, esteja fora de um plano que tipifiquem os papéis sociais, desejos e a maneira como os afetos devem ser sentidos. A proposta de trabalhar a estética dos afetos por meio da arte, diz respeito a um ser humano que tem em sua diferença, algo que saia das tensões verticais entre normal versus anormal, que possa ter na arte um modo de produzir signos e afetos que modifiquem a estética da existência no chamado deficiente e nos demais agentes envolvidos no processo de inclusão escolar.

\section{considerações finais}

Sem a intenção de finalizar o texto, utilizamos este momento para retomarmos pelo processo memorial do pensamento em relação às discussões, a urgente necessidade de repensarmos a arte e o afeto como possibilidade do devir deficiente na escola, ou seja, a inclusão escolar. Para esse estudo, optamos em principio pela discussão e apresentação acerca da arte e a formação conceitual da noção de arte e afeto (affectus) e seus outros componentes conceituais que envolvem a potência e o pensamento não representativo.

Em continuidade, optamos por tratar do devir deficiente na escola (inclusão escolar), principalmente, no contexto da escola comum que, em tais práticas educativas, codifica a experiência do sujeito e reduz sua potência afetiva. Para tanto, a possibilidade de se pensar na escola para a inclusão do ser humano, com dignidade, compromisso, respeito, afeto e ética abre-nos novos horizontes do ensino e da aprendizagem humana, com vistas à linguagem da experiência do diferente, do subjetivo, do indivíduo em suas potencialidades únicas.

Nesse sentido, cabe aos espaços formativos um redirecionamento de suas práticas pedagógicas, superando os discursos sobre inclusão que não se materializam na realidade cotidiana escolar. Para isso, o desafio educacional é problematizar o discurso da inclusão, analisando as condições nas quais emerge o contexto escolar no qual está envolvido, recorrendo aos fundamentos que envolver a dimensão afetiva, a fim de ressignificar as ações docentes e de profissionais em sua totalidade, com vistas ao diferente, ao novo. 
Assim, dentre tantas iniciativas que podem ser desenvolvas, em Deleuze propomos pensar sobre a arte como possibilidade de ampliação da potência afetiva, uma vez que a experiência estética proporciona que os afetos se mobilizem para um olhar diferenciado na forma de perceber e viver a vida de maneira criativa, inventiva, afetiva e social. Fazer da inclusão escolar uma aliança com a potência agir, requer uma compreensão política dos múltiplos dispositivos que atravessam a existência.

Desse modo, o texto buscou apontar os desafios necessários para trabalhar a experiência estética, no sentido de emanciparmos nossos ideais, discursos e ações em relação ao aluno deficiente. Como resultado, acreditamos que, embora, a arte amplie o afeto não apenas naqueles sujeitos considerados possuidores de cultura, mas a apreciação depende de uma percepção sensível e, menos de um pensamento representativo.

\section{referências}

BERGSON, Henri. L'evolution créatrice. Paris: PUF, 1948.

CARVALHO, Alexandre Filordi. Governo da infância e ontologia política do devir deficiente: implicações para a educação. In: VII Colóquio Internacional de Filosofia da Educação, Anais eletrônicos. Rio de Janeiro: UERJ, p. 01-15, 2014.

DELEUZE, Gilles.; GUATTARI, Felix. O que é a Filosofia? Trad. Bento Prado Jr. e Alberto Alonso Muñoz. São Paulo: Editora 34, 1992.

DELEUZE, Gilles. Proust e os signos. Trad. A. C. Piquet; R. Machado. Rio de Janeiro: Forense Universitária, 1987.

DELEUZE, Gilles. Mil platôs: capitalismo e esquizofrenia - vol.1. Trad. Aurélio Guerra Neto e Celi Pinto Costa. Rio de Janeiro: Editora 34, 1995.

DELEUZE, Gilles. Mil Platôs: capitalismo e esquizofrenia - v.4. Trad. Suely Rolnik. Rio de Janeiro: Editora 34, 1997.

DELEUZE, Gilles. Aula sobre Spinoza. Disponível em: http://www.webdeleuze.com/php/texte. php, 1978.

DELEUZE, Gilles. Espinosa: filosofia prática. Trad. Daniel Lins e Fabien Pascal Lins. São Paulo: Escuta, 2002.

FARINA, Cynthia. Arte y Subjetividad en el pensamiento estético deleuziano. In: Arte, cuerpo y subjetividad. Estética de la formación y Pedagogía de las afecciones. (Tese de

Doutoramento - Departamento de Teoría e Historia de la Educación). Facultad de

Ciencias de la Educación, Universidad de Barcelona, p. 1- 408, 2005.

GLEIZER, M. A. Espinosa e a afetividade humana. Rio de Janeiro: Zahar, 2005.

MACHADO, R. Deleuze, a Arte e a Filosofia. Rio de Janeiro, Zahar, 2009.

MIGUEL, Marlon. Guerrilha e resistência em Cévennes. A cartografia de Fernand Deligny e a busca por novas semióticas deleuzo-guattarianas. Revista Trágica: estudos de filosofia da imanência., v. 8, n. 1, p. 57, 2015. 
a arte e o afeto na inclusão escolar: potência e o pensamento não representativo

O'SULLIVAN, Simon. The aesthetics of affect: Thinking art beyond representation. Angelaki: journal of theoretical humanities, v. 6, n. 3, p. 125-135, 2001.

PAGNI, Pedro. Encontros com a Deficiência: de ensaios da ficção a testemunhos sobre a sua ética em uma rede (in) visível. Revista Diálogos e Perspectivas em Educação Especial, v.2, n.1, p. $103-120,2015$.

PAGNI, Pedro. Diferença, subjetivação e educação: um olhar outro sobre a inclusão escolar. Pro-Posições, v. 26, n. 1, p. 87-103, 2015 b.

SLOTERDIJK, Peter. Has de cambiar tu vida. Valência: Pre-textos, 2012.

REBELLO, Hélio. Pragmática menor: Deleuze, imanência e empirismo. 306 f. (Tese de LivreDocência). Faculdade de Ciências e Letras - Assis - UNESP, 2005.

recebido em: 29.08 .2017

aprovado em: 20.02.2018 